\title{
Discussion on Electricity Customers Work of Copy and Acceptance Check in Remote Mountainous Areas
}

\author{
Jingyi Zhang ${ }^{1}$, Xiao Liu ${ }^{1}$, Yingying Yang ${ }^{1}$, Bo $\mathrm{Li}^{1}$, Xinhua Zhao ${ }^{1}$, Chenghao \\ Lan $^{1}$, Yu Meng ${ }^{1}$, Hainan Su' ${ }^{2}$, Xinkun Yang ${ }^{1}$ \\ ${ }^{1}$ Fushun Power Supply Company, Liaoning Electric Power Company Limited, State Grid, China \\ ${ }^{2}$ Dandong Power Supply Company, Liaoning Electric Power Company Limited, State Grid, China
}

Keywords: Mountain Area Power Supply Enterprise, Copy and Acceptance Check, Problems, The Reason, Measures.

\begin{abstract}
The management of Copy and acceptance check work in remote mountainous areas has been the difficulty of power supply enterprises, with the construction of rural power distribution network, constantly improvement of upgrading and renovation work and continuously specification of the power supply enterprise marketing management, most areas of Fushun county made the quality of service and specifications in accordance with the requirements. But there are still a few villages living scattered, so many spots and quite long lines in remote mountainous areas, the electric supply station only manage distribution transformer station area general schedule (gateway meter) or small general schedule of village groups, Copy and acceptance check work of schedules below general schedule or small general schedule is charged by temporary electrician recommended by each village, the villages manage the users below distribution transformer station area, the management level is uneven, there is no uniform management mode, especially the villages with poor management exist masses of public opinion phenomenon. In this article, copy and acceptance check of fushun power supply branch management present situation and existing problems was expounded, and analyzed the causes of these problems and put forward the corresponding solutions.
\end{abstract}

\section{Introduction}

Electricity Copy and acceptance check management refers to the account pricing, meter reading, Receivables audit, paid-in billing, charging, Electricity Tariff Management, Electricity statistical analysis and report submitting of the power supply business management and the management of electricity charge, data and information. Its task is to strictly implements the Electricity Tariff policies issued by national and the higher relevant departments, timely and accurate copy and calculate, fully recovery and hand in the electricity [4].

Electricity Copy and acceptance check work of the urban population concentrated is also a difficult task, Fushun county is located in the western of Fushun city, east to XinBin Manchu autonomous county, south to Xihu area and Benxi Manchu autonomous county, Shenyang dongling district, Sujiatun district, fushun city, Shuncheng district in the west, Tieling county to the north, northeast and bordering with Qingyuan Manchu autonomous county .It's area is about 2200 square kilometers, continuation of the southwest area of Changbai mountains, located in transition zone of low hills to the plain. High in southeast, low in northwest, hilly territory, average elevation 100-300 meters, the water is abundant, the main rivers are Hunhe river and its tributaries Danghe river, local river, Dongzhou river, etc. The soil is fertile and dense forest, all kinds of resources is very rich. Fushun is geographically both the plain and mountainous areas, all products of work, agriculture, forestry, animal husbandry and fish resources are fully available, the total population is 190 thousand people, Fushun county governs four towns and eight townships: ShiWen Town, after Ann town, chapter party town, hadad town, horse circle township, the horse township, reinforcements township, gorge river township, the wave river township, the laguna manchu township, Lanshan township, Soup figure manchu township. 


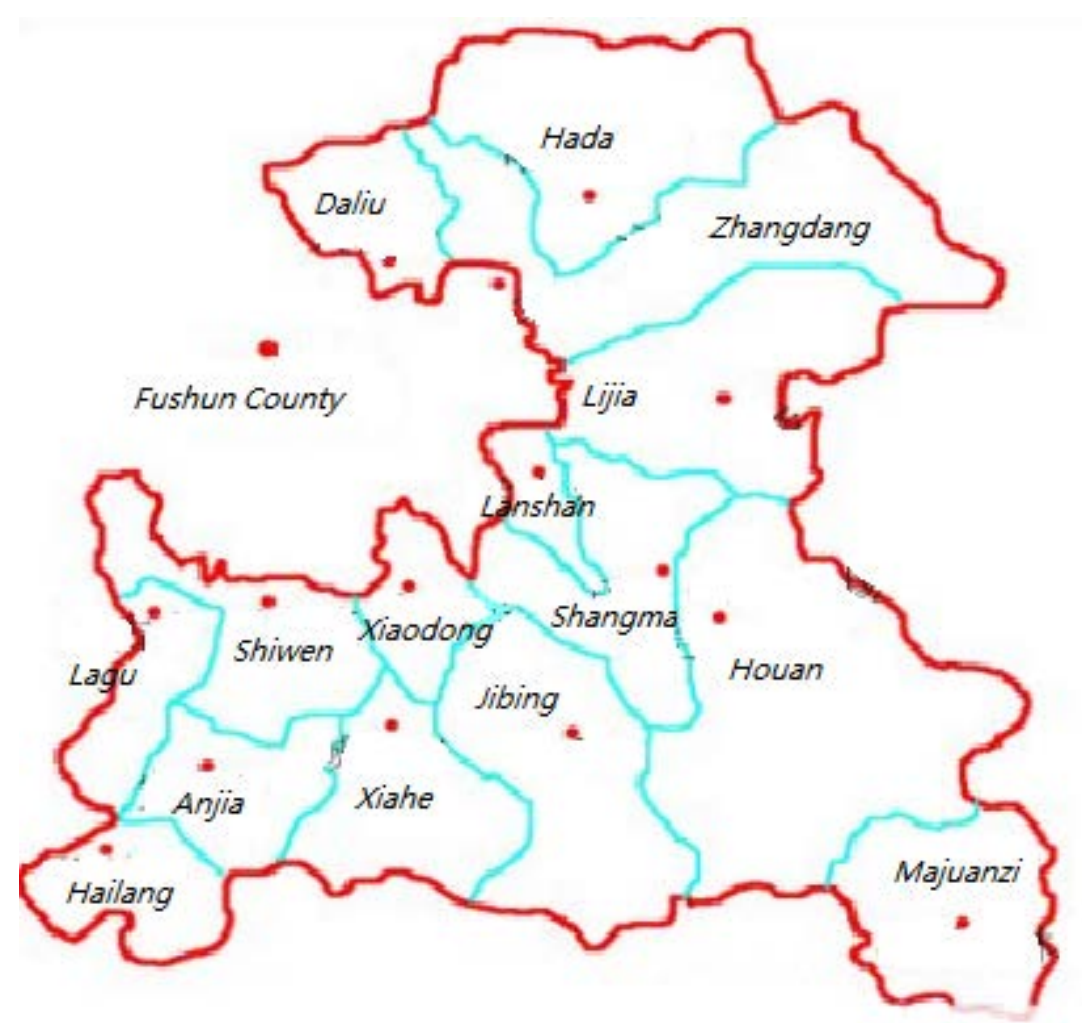

\section{The Status of Copy and Acceptance Check Management}

With the construction of rural power distribution network, constantly improvement of upgrading and renovation work and continuously specification of the power supply enterprise marketing management, most areas of Fushun county made the quality of service and specifications in accordance with the requirements of "five unified, four households, three open". But because of the special geographical environment and the characteristics of the population living scattered in remote areas of Fushun county, in addition power supply enterprise is restricted by various factors such as personnel, financial, and material resources factors and the application of new technology and new equipment, there are still a few villages living scattered, so many spots and quite long lines in remote mountainous areas does not realized the management directly to the household by electric supply station and continue to implement village self management mode, namely the electric supply station only manage distribution transformer station area general schedule (gateway meter) or small general schedule of village groups, Copy and acceptance check work of schedules below general schedule or small general schedule is charged by peasant contract worker recommended by each village (hereinafter referred to as temporary electrician). Because of this management mode is still exist many problems and deficiencies, so how to solve these problems and how to take effective measures is the current focus and difficulty.

\section{The Existing Question}

In terms of Fushun county, the village that power supply enterprises does not implement the Copy and acceptance check work household management directly are mostly traffic inconvenience, sparsely populated, living scattered and harsh natural conditions. Segment personnels in these places are only responsible for distribution transformer station area general schedule monthly, minus approved low voltage line loss power from general schedule as the charging power, household electricity below general schedule is charged by temporary electrician. As the villages 
manage the users below distribution transformer station area, the management level is uneven, there is no uniform management mode, especially the villages with poor management and masses of public opinion, the Copy and acceptance check work currently has widespread problems as follows[5]:

(1)Low voltage line loss is generally high, low voltage line loss of the area is up to $25 \%$. Such as the electrical transformer district in Hada town NO.2 Mazhou village, Taoyuan village, Yao ditch town van fishing village brick dam. Etc.

(2)Self management the villages exist different degrees of human power, relationship power, right power phenomenon and extra charge meter reader salary phenomenon, leading the electricity to household electricity price is higher.

The electricity price of these villages is generally $0.55 \sim 0.70$ yuan, public opinion is bigger, temporary electricians because of work is difficult are not willing to continue to management.

(3)County peoples congress representatives and CPPCC members often put forward the Suggestions and proposals on county NPC and CPPCC, request to solve these problems thoroughly.

Although in recent years, the county power supply enterprises through unremitting efforts and a lot of work, take some measures to increase the network and remote set copy work effort, enlarged the scope of meter reading directly to households, but there are still a small number of villages restricted by various conditions temporarily unable to manage to the household by power supply enterprises, there are still still exist problems like high line loss, high price to the household and poor management and easy to rebound need to thoroughly solve.

\section{Reason Analysis}

The main problem of the power supply enterprise who is not straight to the village households of distribution transformer station area village is mismanagement, high line lose, high household price, the reason are as followings:

(1)As the restriction of the power grid construction and reforming early capital restrictions, the network reformation of low-voltage line in these parts of the villages are not complete or not transformation, at the same time in the process of reformation in the power grid construction because of low line construction technology standard, not unified standards and other factors, led to the current line aging, small diameter, broken strands, the user lines messy, card neck line, line loss is too large, and poor reliability of power supply.

(2)Measuring instrument assets belong to the user, because of poor mountainous areas economy, resulting in " a door a table" reformation is difficult and more loans, coupled with the early network reformation meter technology is not standardized, even without reform, the old mechanical watch was in common use, after more than 10 years operation, electric energy meter of individual user has been bad in some places, meter has not periodically check for many years, inaccurate measurement and great table loss. Such as in Hada distribution transformer loss is as high as $20 \%$, household price is 0.65 yuan or so, the main reason is "a door a table" reformation is not standardized or not transformation at all.

(3)Mountain high and deep, fewer users and live too remote and scattered, low voltage power supply radius is too long, serious exceed the standard, in some places even more than $5 \mathrm{~km}$, the end of the line voltage is low voltage, low voltage qualified rate resulting in high line loss. Such as radius of low voltage line of small stockade, Bei San Jia $\mathrm{Zi}$ is more than $4 \mathrm{~km}$, the line loss exceed $25 \%$, the price reached 0.70 yuan or so.

(4)Part of the village power management personnels are without villagers recommended and temporary electricians are designated by the village cadres, some fee collectors charged labor remuneration from each household, the standard charge is vary, combined with the village electricity consumption is too small, the average share price is high. Such as Heqing village distribution transformer, three villagers group a total of 33 households, the reading time needs three whole day; closed mountain village 10kVA distribution transformer, 8 users, average monthly electricity more than 70 degrees, needs for two days reading time; Gu Tang village 10kVA 
distribution transformer, 11 users and monthly sharing electricity more than 180 degrees, needs for two days reading time.

(5)Part of the village's temporary electricians have poor sense of responsibility. Go in tolling the bell as long as one is a monk, neglected management maintenance, resulting in the tree barrier, meter damage and inaccuracy metering serious phenomenons, combined with not strict and unfixed metering period, line loss is unstable, charging price fluctuated. Such as Darfur town south ditch village, green ShiLing Village, Aji village are implementing the way of users take turns for metering.

(6)There exist different degrees of human power, relationship power, right power phenomenon, especially the temporary electricians of the village and their relatives and friends are not measured and unpaid, the phenomenon of all assessed to the electricity price is more common.

(7)As the remote mountain village users live remote and scattered, when in busy farming and specialties production season for mushrooms, fungus they need temporary electricity, the users directly hang the wires to the low voltage line with hook, existing stealing electricity phenomenon, because of the temporary use of electricity always in short time, the location is not fixed, so it is difficult to deal with.

(8)Due to individual power supply line is village self assets, assets is not definitely transferred to the power supply enterprise, leading the line assets attribution is not clear, the power supply and villages mutually shuffling, daily operation and management is not in place and complete, the tree barrier and leakage phenomenon is serious.

\section{The Ideas and Measures to Solve the Problem}

Solve the problem of mismanagement, high line lose and high household price of the power supply enterprise who is not straight to the village households of distribution transformer station area should depend on the power supply enterprise, the local town government and village cadres and the masses of various forces, according to the different reasons take different measures to deal with [1].

(1) Whether the power supply enterprises directly to the household, should continue to increase efforts to upgrade the rural power grid. Combine with the southern Shanxi area resettlement project, strictly accordance with the requirements of technical specifications, upgrading the power grid of the villages whose original grid foundation is weak, not completely and no network reconstruction, effectively solve the problems of old electric power facilities, aging lines and other existing security risks, improve power quality and qualified rate, especially "a door a table" reformation should be synchronized, elimination and replace the unqualified electric energy meter, specified table wiring standards, strengthen measurement management, achieve the purpose of reducing loss.

(2) Power supply enterprises should overcome the difficulties of human financial and material, in the places where users are relatively concentrated and permitting conditions areas should change villagers self management into direct management of power supply. In the current circumstances of enterprise manpower shortage and hard to supplement, extending monthly metering time or implementation $\mathrm{Bi}$ monthly and quarterly metering can be adopted, expand the range of household metering.

(3) Increase capital investment, assets investment shall be the responsible for power supply enterprises, vigorously carry out the remote collecting prepaid meter, use technical measures to solve the power supply problem of insufficient manpower to the household, this is also an ideal way to solve the direct copy of households.

(4) The villages temporarily still can not metering to the household can elect strong sense of responsibility personnels by the masses to charge electricity fees and relatively fixed, and strengthen supervision and inspection. Power Supply Station should assist the village cadres, NPC deputies and CPPCC members and the masses representatives to strengthen the management, eliminate the "three electricity" phenomenon, measure area low voltage line loss commonly, approved a reasonable electricity price to households and remuneration of village electricity collectors, open and transparent and public monthly. Such as distribution transformer station area of 
eyes gorge river town, xiao Lin, du home, big house, six row houses, sanjiazi, by adopting the way of grid upgrading, strengthen management, meter rotation check, eliminate the unqualified electric energy meter, clean up the tree barrier, put an end to "three electricity" phenomenon, regulate the use of electricity, approved reasonable village electrician remuneration and strengthen supervision, open and transparent, although the power supply has not yet been straightly manage to the household, but the price has transformed from 0.70 yuan before reformation and supervision now reduced to 0.50 to 0.60 yuan.

(5) The power supply enterprise surrender part of the profits to the masses, truthfully check and ratify low voltage line loss of areas and bear the loss by power supply enterprises.

(6) The village charge electricians are service for the masses, under the conditions of permitting, the remuneration of electricians are paid by the village to reduce the burden of users.

\section{Conclusions}

The problem of Power supply enterprises are not straightly to the household at present is relatively common in fushun remote mountainous areas, how to solve this problem requires the joint efforts of all sectors of society and actively create conditions, especially the power supply enterprise need to strengthen the investment of human financial and material and technical measures, through meticulous work to obtain the understanding and support of all parties and achieve tangible results. Otherwise, because of the electricity copy and acceptance check management confusion, cause villagers complain and trouble often occurs, disrupting social order, affect the stability and unity of the residents.

\section{References}

[1] Jinkai Huangr. The rural electricity management manual. Shenyang: Liaoning science and Technology Press.1989

[2] Xueqi Liao. Theoretical calculation of line losses and loss management. Beijing: Education Science Press.1990

[3] Yilu Qi. Energy conservation technology handbook. Beijing: China power press.1998

[4] Zhe Jin. Energy saving technology and energy saving technology. Beijing: China power press.1999 